\title{
Intensification of grinding technology and methods for studying the structure of fibrous materials in the process of its production
}

\author{
Aidar Saetshin ${ }^{1, *}$, Zimfira Valishina ${ }^{1}$, Evgenie Matuhin², and Anatoliy Kostochko ${ }^{1}$ \\ ${ }^{1}$ Kazan National Research Technological University, Kazan \\ ${ }^{2}$ FKP "Kazan State Gunpowder Plant", Kazan
}

\begin{abstract}
One of the most important indicators of the suitability of new types of fibrous materials for processing in products with specified properties is the degree of grinding. A detailed analysis of the influence of various factors on the quality of grinding of fibrous materials was carried out. The information is necessary for predicting the properties of new types of materials and controlling the technological process for obtaining fibrous materials with improved and controlled characteristics. The advantages of a modern method for analyzing the properties of fibers in the process of obtaining new types of materials are shown, which makes it possible to evaluate the active fiber surface and its fractional composition.
\end{abstract}

The grinding phase plays a significant role in producing the nitrate ester of cellulose [1-3].

Control process principles of grinding the different types of nitrocellulose (NC) are based on abstract content about processes of fibrous materials grinding. It is set on the basis of systematic researches and the revealed dependence connecting the fractional composition of $\mathrm{NC}$ with technological parameters of grinding process and structural-morphological properties of $\mathrm{NC}$, rate of plastification and the quality of NC compositions [4-6].

The main purpose in this phase is to obtain the NC fibers with the necessary geometrical sizes, that provide fast invasion of wash liquids in fibers and removal from channels the encapsulated acids remained after previous stages of stabilization process. When grinding fibers in the water, the change of their structural properties is happened. Therefore the term "grinding" doesn't reflect the essence of technical and technological processes in installations like cylinder engine, conical and other mills.

The existing technological processes and mechanism don't allow to obtain fibrous materials, in particular the nitrate esters of cellulose homogeneous in fractional composition [3].

The problem of increasing the homogeneity and stability of properties according to solubility, molecular weight of $\mathrm{NC}$ is relevant in connection with the expansion of the scope and tightening of requirements on new types of nitrate esters of cellulose (table 2). The increase of NC quality characteristics is possible due to the optimization of the technological process or modernization of production.

The main experimental data on investigation of grinding mechanism of $\mathrm{NC}$ fibrous in working parts of knife machine are described in this paper. Also presented the principle of fiber processing in various grinding mechanisms and issues related to the analysis of $\mathrm{NC}$ morphological structure with the help of modern analyses method of fiber properties.

For NC grinding are currently used the conical mills (RK-01) and disk mills DMK (disk mill Kuzmina), differing by the principle of grinding. When grinding in conical mill, the fiber is "become ground" and in the result the NC has "ground" surface. When grinding in the DMK the fiber is generally cut. The Impact on the fiber during grinding effects characteristics of products [9-10].

The impact of grinding method on proper-ties of obtained NC has been confirmed in case of the study of thermo mechanical properties and kinetics of nitrate ester cellulose swelling on the basis of cotton and wood cellulose (table 1).

The presented results of the study in the table 2 show that the grinding method effects on technical and technological NC properties, affecting the quality on received NC compositions.

Table 1. The impact of grinding method on physical, chemical and technological characteristics of cellulose nitrates, received from various types of raw materials [4].

\begin{tabular}{|c|c|c|c|c|c|}
\hline cellulose & $\begin{array}{l}\text { Type } \\
\text { of mill }\end{array}$ & $\begin{array}{l}\text { Nitrogen } \\
\text { content, } \\
\text { ml NO/g }\end{array}$ & $\begin{array}{l}\text { Vis } \\
\text { cosi } \\
\text { ty, } \\
\mathrm{E}\end{array}$ & $\begin{array}{l}\text { Sieve } \\
\text { analysis } \\
\text { (sieve 0,16 } \\
\%\end{array}$ & $\begin{array}{l}\text { Degree } \\
\text { of } \\
\text { swellin } \\
\mathrm{g} ; \Delta \mathrm{V}\end{array}$ \\
\hline $\begin{array}{c}\text { Cotton } \\
\text { cellulose }\end{array}$ & RK-01 & 191.4 & 2.0 & 1.0 & 0.50 \\
\hline $\begin{array}{c}\text { Bleached } \\
\text { Dulfite }\end{array}$ & RK-01 & 191.8 & 2.5 & 2.3 & 0.35 \\
\hline
\end{tabular}

Insufficient knowledge regarding the mechanism of grinding $\mathrm{NC}$, especially in the way of impact of driven elements on fiber, and also the current mechanization of grinding phase, doesn't allow to prepare the fiber for plastification [7-8].

\footnotetext{
*Corresponding author: aidar.saetschin@yandex.ru
} 
By grinding $\mathrm{NC}$ with high degree substitution in DMK, the fractional composition depends on the way of input and removing of $\mathrm{NC}$ water suspension from machine. By grinding $\mathrm{NC}$ on the scheme "under pressure", the aver-age length of fiber is $0.168 \mathrm{~mm}$, bulk mass is $108 \mathrm{~kg} / \mathrm{m}^{3}$. By grinding on the scheme "free flow", the average length of fiber is $0.131 \mathrm{~mm}$, bulk mass is $128 \mathrm{~kg} / \mathrm{m}^{3}$. By grinding in conical mill RK-01 due to the multiple passes through crushing knives the average length of fiber is $0.207 \mathrm{~mm}$, bulk mass is approximately $108 \mathrm{~kg} / \mathrm{m}^{3}$.

By grinding in DMK on the scheme "under pressure", by increasing the suspension concentrates from 4 to $8 \%$, the fraction content with the size of fiber $0.16 \mathrm{~mm}$ is increasing from 0 to $27 \%$. This is because the increasing of suspension concentrate of $\mathrm{NC}$ products leads to the increasing of $\mathrm{NC}$ stay period in mechanism through speed reduction of mass flow. For this purpose the probability of fiber breakthrough across knives-edges reduces. At the same time the $\mathrm{NC}$ fractional composition is directly linked to suspension concentrate. The higher is the concentration, the greater the degree of NC grinding.

Table 2. Physico-chemical characteristics of analyzed nitrates of cellulose.

\begin{tabular}{|l|c|c|}
\hline \multirow{2}{*}{ Indicator name } & \multicolumn{2}{|c|}{ NC } \\
\cline { 2 - 3 } & №1 & №2 \\
\hline Raw material input & \multicolumn{2}{|c|}{ Cotton cellulose } \\
\hline Nitrogen content, \% & 13,1 & $11,8-12,5$ \\
\hline $\begin{array}{l}\text { Degree of grinding: } \\
\text { sieve residue 016,\% }\end{array}$ & Max 7 & Max 9 \\
\hline
\end{tabular}

The fractional composition of NC №1 и №2 (table 2) is established in DMK (figure 1) [11] depending on handling time and load intensity. The figure 1 shows that by increasing the grinding time and DMK engine load, there a significant reduction of fraction with the length of fiber more than $0.5 \mathrm{~mm}$. There is also a notable increase in fractional composition due to the grinding in DMK under engine load more than $180 \mathrm{~A}$.

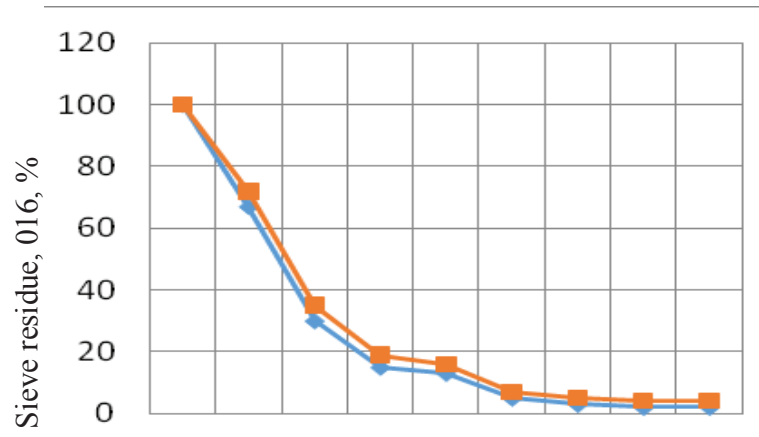

90100110120130150160180210

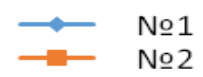

Load, A

Fig.1. The quality of cellulose nitrate grinding by the method of sieve residue 0.16 when grinding in DMK.

On the basis of the above, it may be concluded that it is necessary to use a special mechanism that would not only cut fibers, but brush them for receiving required parameters in the clarity of grinding during the $\mathrm{NC}$ grinding [12].

The degree of grinding alongside with viscosity, solubility, degree of etherification and molecular weight distribution is the one of the most important characteristics of quality that determines technological properties of $\mathrm{NC}$ and nitrate cellulose compositions (table $3)$.

Table 3. Comparative characteristic of physico-chemical and structural properties of $\mathrm{NC}$ with analog.

\begin{tabular}{|l|c|c|c|}
\hline Indicator name & $\begin{array}{c}\text { sampleNC } \\
\text { №2 } \mathrm{C}^{\mathrm{x}}\end{array}$ & $\begin{array}{c}\text { New type of } \\
\text { NC }\end{array}$ & \multirow{2}{*}{ analog } \\
\cline { 3 - 3 } & & $\begin{array}{c}\text { NC sample } \\
\text { № 1-01 }\end{array}$ & \\
\hline $\begin{array}{l}\text { Nitrogen content, } \\
\%\end{array}$ & 13.21 & 13.2 & $13.17-13.3$ \\
\hline Viscosity, mPas & 15.7 & 57 & $45-60$ \\
\hline Bet, $\mathrm{m}^{2} / \mathrm{g}$ & 8.71 & 7.3 & \\
\hline $\begin{array}{l}\text { solubilityalcohol/e } \\
\text { ther, \% }\end{array}$ & 5.1 & 28.3 & $28-35$ \\
\hline $\begin{array}{l}\text { Solubility in } \\
\text { alcohol, \% }\end{array}$ & 1.0 & 1.3 & Max 3 \\
\hline $\begin{array}{l}\text { Grinding degree: } \\
\begin{array}{l}\text { Fibre volume, } \\
\text { ml/10g }\end{array}\end{array}$ & 108 & 98 & Max 95 \\
\hline
\end{tabular}

x) For NC grinding (Sample № 2C) the conical mill RK-01 is used

To date, it is necessary to give the correct assessment to the degree of $\mathrm{NC}$ grinding. Until recently there has been a lack of reliable method of quality assessment for $\mathrm{NC}$ grinding. The current methods (volumetric method, "artillery sample", sieve method) don't provide with complete information on grinding quality and don't allow to define the main factors, affecting on the process of $\mathrm{NC}$ qualities formation with improved characteristics. Atthepresenttimethenewmethodisused [13-15].

The use of new method of NC morphological structure analyses is necessary for establishing the connection among particle sizes, structure and qualities of nitrate cellulose products.

This method allows to analyze samples with the provision of data on the fiber sizes (length, width), grain characteristics, coarseness, fiber contortion and other parameters of morphological structure of fiber and grains.

The principle of measurement is following: high resolution camera captures halftone images from which the analyzer calculates the different properties of fiber with the help of images analyses. The image of sample fibers is created in a measuring cell with depth of sharpness of $0.5 \mathrm{~mm}$ according to the standard ISO 16505-2. The length of fiber is measured along axis of fiber symmetry. Due to this the accuracy of measurements of the contorted and retorted fibers is ensured. Besides, for the calculations of deformations the projection length of fiber is measured (the linear distance among fiber points which are in the longest distance one from another).

The results of analyses are presented in the tables $(4,5,6,7,8)$ and figures $(2,3,4,5)$. 
Table 4. Distribution of fractions to length, width and mass for NC № 1-01 on the basis of modern analyses method.

\begin{tabular}{|c|c|c|c|}
\hline $\begin{array}{c}\text { Fractional } \\
\text { composition, } \mathrm{mm}\end{array}$ & $\begin{array}{c}\text { Length, } \\
\%\end{array}$ & $\begin{array}{c}\text { Mass, } \\
\%\end{array}$ & Width, \% \\
\hline $1: 0-0.2$ & 27.8 & 25.1 & 16.1 \\
\hline $2: 0.2-0.6$ & 54.7 & 56.3 & 17.4 \\
\hline $3: 0.6-1.2$ & 16.3 & 17.3 & 17.8 \\
\hline $4: 1.2-2.0$ & 1.2 & 1.3 & 17.6 \\
\hline $5: 2.0-3.2$ & 0.1 & 0.1 & 19.0 \\
\hline
\end{tabular}

Table 5. The results of sample processing NC №1-01.

\begin{tabular}{|l|c|}
\hline Coarseness, $\mathrm{mg} / \mathrm{m}$ & 0.098 \\
\hline Twist, \% & 22.94 \\
\hline Flaked grains A, \% & 35.22 \\
\hline Laminar grains B, \% & 5.79 \\
\hline $\begin{array}{l}\text { Grains in percentage from } \\
\text { weighted average, \% }\end{array}$ & 67.05 \\
\hline Width of fiber, mkm & 17.5 \\
\hline
\end{tabular}

Table 6. The average length of fiber for sample NC №1-01.

\begin{tabular}{|l|c|}
\hline \multicolumn{1}{|c|}{ Average length of fiber } & Value \\
\hline Lc(n) Arithmeticaverageoffiberlength, $\mathrm{mm}$ & 0.179 \\
\hline $\mathrm{Lc}(\mathrm{l})$ Weightedaveragetofiberlength, $\mathrm{mm}$ & 0.381 \\
\hline $\mathrm{Lc}(\mathrm{w})$ Weightedaveragetofibermass, $\mathrm{mm}$ & 0.574 \\
\hline
\end{tabular}

Table 7. Distributions of fractions to length, width and mass for NC № 2Con the basis of modern analyses method.

\begin{tabular}{|c|c|c|c|}
\hline $\begin{array}{c}\text { Fractional } \\
\text { composition, } \mathrm{mm}\end{array}$ & $\begin{array}{c}\text { Length, } \\
\%\end{array}$ & $\begin{array}{c}\text { Mass, } \\
\%\end{array}$ & Width, \% \\
\hline $1: 0-0.2$ & 45.8 & 41.4 & 16.9 \\
\hline $2: 0.2-0.6$ & 48.3 & 52.7 & 18.7 \\
\hline $3: 0.6-1.2$ & 5.6 & 5.7 & 18.3 \\
\hline $4: 1.2-2.0$ & 0.3 & 0.2 & 16.3 \\
\hline
\end{tabular}

Table 8. The results of sample processingNC №2C.

\begin{tabular}{|l|c|}
\hline Coarseness, $\mathrm{mg} / \mathrm{m}$ & 0.110 \\
\hline Twist, \% & 21.39 \\
\hline Flaked grains A, \% & 52.17 \\
\hline Laminar grains B, \% & 4.23 \\
\hline $\begin{array}{l}\text { Grains in percentage from } \\
\text { weighted average, \% }\end{array}$ & 78.61 \\
\hline Fiber width, mkm & 16.8 \\
\hline
\end{tabular}

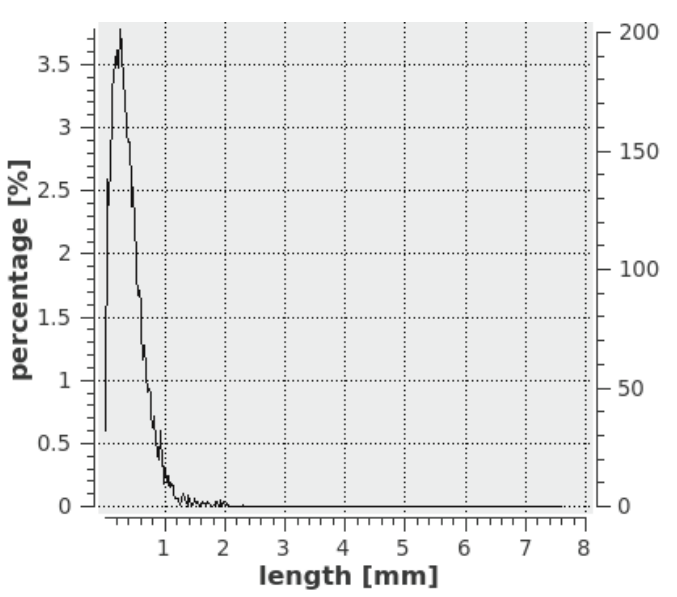

Fig. 2. Weighed average distribution to grain length of sample № 1-01.

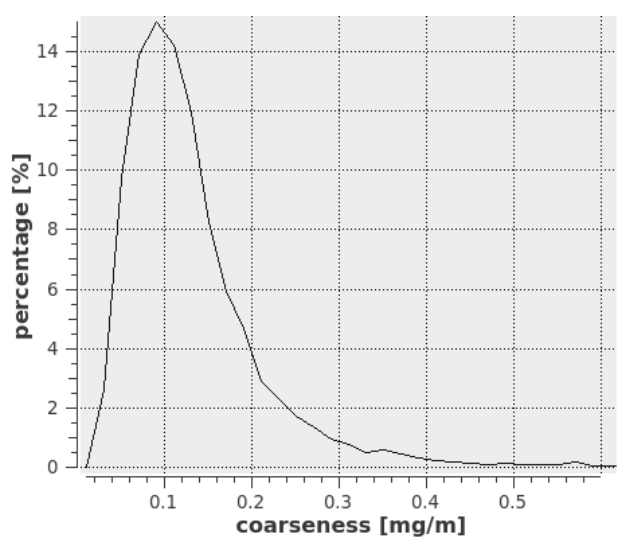

Fig. 3. Distribution to coarseness for sample NC № 1-01.

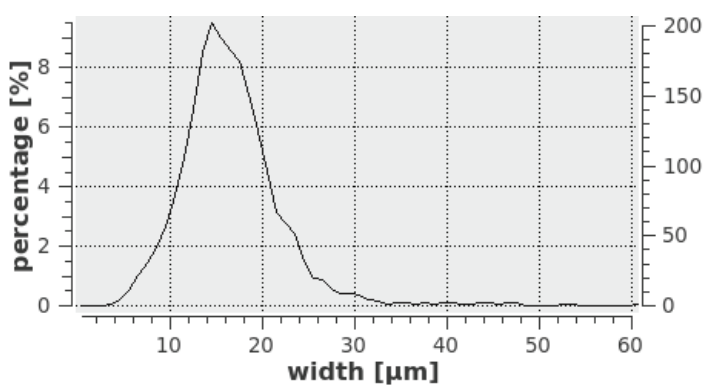

Fig.4. Distribution to width of fibre for sample NC №2C.

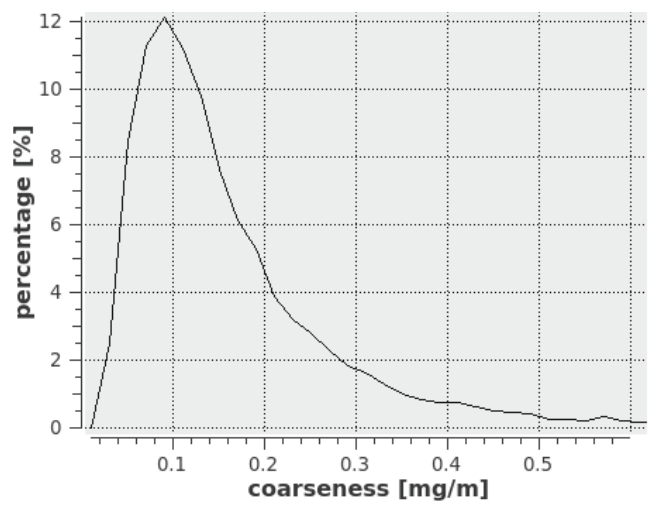

Fig. 5. Distribution to coarseness for sample NC № 2C.

Consequently, the use of appropriate grinding mechanism will allow to receive $\mathrm{NC}$ with homogeneous properties by gravimetric density, structure, active area,fractional composition, polymerization degree, speed of plasticizer absorption and nitrate cellulose compositions with improved mechanical characteristics.

The modern method is characterized by accuracy, informativity and there is a possibility to use it as express method.

\section{References}

1. V. I. Gindich, L.V. Zabelin, Production of cellulosenitrates. Technology and equipment (1984)

2. A.V.Kostochko, B.M. Kazban, Powders, solid rocket fuel and its propert ies (2015)

3. Z.T. Valishina, A.A. Saetshin, V.G. Borbuzanov, N.Kh. Giniyatov, E.L. Matukhin, A.V. Kostochko, 
Structure and properties of a new type of cellulose nitrate with improved characteristics, Ammunition, Scientific and technical collection of the State Scientific Center of the Federal State Unitary Enterprise "TsNIIKhMim. DI. Mendeleev", 2, 31 (2016)

4. G.M. Marchenko, M. Zabelin, Production of nitrates of cellulose. Physical and chemical foundations of production and processing of cellulose nitrates (1988)

5. V.I. Kovalenko, O.V. Mikhailov, G.M. Khrapkovsky, Cellulose nitrate: molecularstructural heterogeneity (2003)

6. V.M. Lebedeva, A.S. Semochkin, D.M. Kaganov, Intensification of the process of dehydration of cellulose nitrates on centrifuges of periodic action, Proceedings AII-Russian. Conf. RCTUthem. DIMendeleev, 452 (2010)

7. V.I.Gindich, Production of cellulose nitrates and of acids regeneration (1995)

8. Z.T. Valishina, A.A. Saetshin, V.G. Borbuzanov, E.L. Matukhin, A.V. Kostochko, Structure and properties of high-quality dispersed cellulose nitrates, Materials of the VIII All-Russian Conf., , 157 (2016)

9. A.A. Saetshin, Z.T. Valishina, E.L. Matukhin, I.I.Malov, G.N. Galiullina, A.V. Kostochko, Method for Investigating the Morphological Structure of Powder Celluloses, Bulletin of the Kazan Technological University, 18, 103 (2016)

10. A.A. Saetshin, A.Yu. Nizami, F.T. Valishina, F.T.Yusupov, V.G. Borbuzanov, E.L. Matukhin, Z.T. A.V. Kostochko, Equipment and Materials, Technologies and equipment for pulverizing of cellulose-containing material, Materials of the International Scientific and Technical Conference "Innovative Engineering Technologies, 1, 154 (2016)

11. F.T. Yusupov, A.A. Saetshin, V.G. Borbuzanov, E.L. Matukhin, Z.T. Valishina, A.V. Kostochko, Improvement of technology and equipment for the modification of cellulosic materials (separation, aggregation, conditioning, Materials of the International Scientific and Technical Conference "Innovative machine-building technologies, equipment and materials, 1, 234 (2016)

12. A.A. Saetshin, Z.T. Valishina, E.L. Matukhin, A.V. Kostochko, A modern method for analyzing the properties of cellulose-containing materials, Ecological problems of economic subjects: a collection of the VI International Scientific and Practical Conference, 77 (2016)

13. A.A. Saetshin, Z.T. Valishina, E.L. Matukhin, A.V. Kostochko, A modern method for investigating the properties of high-quality dispersed celluloses and nitrate esters of cellulose, Collection of abstracts of reports "Modern problems of special technical chemistry, 30 (2016)

14. A.A. Saetshin, Z.T. Valishina, E.L. Matukhin, G.N. Galiullina, I.I. Malov, A.V. Kostochko, Reagents and materials for construction, operation and repair of oil, gas and gas condensate wells: production, properties and experience of application, Materials of the XX International Scientific and Practical Conf., 106 (2016)

15. Z.T. Valishina, A.V. Kostochko, O.T. Shipin, R.F. Gatina, Yu.M. Mikhailov, Structure and properties of new types of nitrate esters, Vestnik Kazanskogo tekhnol.un-ta, 9, 281 (2010) 